\title{
Epizootic Hemorrhagic Disease Virus Serotype 6 Infection in Cattle, Japan, 2015
}

\author{
Yuka Kamomae, Masahiro Kamomae, \\ Yasuyuki Ohta, Mikoto Nabe, Yuichi Kagawa, \\ Yuji Ogura, Tomoko Kato, Shogo Tanaka, \\ Tohru Yanase, Hiroaki Shirafuji
}

During October-December 2015, an epizootic hemorrhagic disease outbreak occurred in cattle in Japan. Forty-six animals displayed fever, anorexia, cessation of rumination, salivation, and dysphagia. Virologic, serologic, and pathologic investigations revealed the causative agent was epizootic hemorrhagic disease virus serotype 6 . Further virus characterization is needed to determine virus pathogenicity.

E pizootic hemorrhagic disease virus (EHDV; genus Orbivirus, family Reoviridae) is an arthropodborne virus that is transmitted among ruminant hosts by the bite of Culicoides midges (1-3). EHDV infection of wild and domestic ruminants has been reported in the Americas, Africa, Asia, Australia, the Middle East, and some islands of the Indian Ocean (1) and affects primarily white-tailed deer (Odocoileus virginianus) and cattle (1-3). EHDV infection in cattle does not usually result in clinical disease, but clinical cases of epizootic hemorrhagic disease in cattle have been reported in several countries in Asia, Africa, and the Middle East (1-5).

EHDV serotype 2 (EHDV-2) strain Ibaraki virus was first identified in affected cattle in Japan in 1959. Ibaraki virus has caused disease repetitively in cattle, with signs and symptoms including fever, anorexia, nasal and ocular discharge, congestion of conjunctival and nasal mucous membranes, swollen eyelids and tongue, and dysphagia $(4,6)$. A large-scale epidemic of atypical Ibaraki disease also occurred in Japan in 1997; the epidemic caused mainly abortion and stillbirth in cattle, and the causative agent was found to be EHDV-7 $(7,8)$. Several strains of EHDV1, EHDV-7, and EHDV-10 were also observed in Japan but did not appear to be associated with clinical disease in cattle $(8)$.

Author affiliations: Awaji Livestock Hygiene Service Center, Minamiawaji, Japan (Y. Kamomae, Y. Ohta, Y. Kagawa); Himeji Livestock Hygiene Service Center, Himeji, Japan (M. Kamomae, M. Nabe, Y. Ogura); National Agriculture and Food Research Organization, Kagoshima, Japan (T. Kato, S. Tanaka, T. Yanase, H. Shirafuji)

DOI: https://doi.org/10.3201/eid2405.171859
In October 2015, an outbreak of febrile illness occurred in cattle in Hyogo Prefecture, Japan, and lasted 3 months. We summarize the features of this outbreak, which affected 46 cattle at 38 farms.

\section{The Study}

Of the 46 affected cattle, 40 were beef cattle (Japanese Black) and 6 were dairy cattle (Holstein heifers). The average age of all affected animals was 114.7 (range 11-187) months. The clinical signs observed in beef cattle were fever, anorexia, cessation of rumination, swollen eyelids, salivation, paralysis of the tongue, difficulty swallowing, nasal and ocular discharge, and abortion (Table 1). Seven beef cattle died, and 2 were euthanized because they did not recover despite treatment of symptoms. The dairy cattle showed fever, anorexia, coughing, conjunctivitis, cessation of rumination, salivation, difficulty swallowing, and reduced milk production.

Early in the outbreak, Ibaraki disease was suspected, so blood samples were collected. We washed the blood cells and used them for virus isolation and reverse transcription PCR (RT-PCR) for group-specific and serotypespecific EHDV detection $(9,10)$. Paired serum samples were also collected from 20 of the 46 affected animals at early onset of the outbreak and after the outbreak at 1- or 2 -month intervals. We used the paired serum samples for neutralization tests and conducted necropsies on 2 euthanized animals.

All 46 of the affected animals tested positive for EHDV by group-specific RT-PCR (9) and EHDV-6 by serotype-specific RT-PCR (10), although we did not isolate infectious virus. The neutralizing antibody titers of serum samples acquired after the outbreak $(n=20)$ were 1: $\geq 32$ for EHDV-6 strain AUS1981/07 CSIRO 753 (Table 2 ). The neutralization test also showed increases ( $\geq 4$-fold) in EHDV-6 antibody titers for paired serum samples of 5 cattle (nos. 6, 7, 10, 11, and 13), although such increases were not observed in the other 15 cattle (Table 2).

At necropsy, we observed edema of the esophagus, pharynx, and tongue in an affected cow with dysphagia. The lumen of the esophagus was also dilated (Figure 1, panel A). The histopathologic lesions included hyaline degeneration and necrosis of striated muscle accompanied by cell infiltration in the esophagus and tongue (Figure 1, panel B), thrombosis of small vessels, a proliferation of connective tissue in the esophagus, and necrosis of striated 
Table 1. Clinical manifestations of affected cattle during epizootic hemorrhagic disease outbreak, Japan, 2015

\begin{tabular}{lc}
\hline Clinical sign & No. cattle \\
\hline Anorexia & 38 \\
Fever & 28 \\
Cessation of rumination & 22 \\
Salivation & 20 \\
Difficulty swallowing & 19 \\
Swollen eyelids & 8 \\
Coughing & 3 \\
Conjunctivitis & 3 \\
Reduced milk production & 3 \\
Abortion & 2 \\
Ocular discharge & 1 \\
Death & $9^{*}$ \\
\hline *Includes 2 euthanized cattle. &
\end{tabular}

muscle in the pharynx. We conducted immunohistochemical assays with necropsy tissue samples from this cow using rabbit antiserum against EHDV-6 AUS1981/07 CSIRO 753 and detected antigen in the vascular endothelium of the esophageal muscle layer (Figure 1, panel C).

We further characterized the causative agent by performing sequence analysis of genome segment 2, which correlates with serotype, and segment 3 , which correlates with geographic genetic type, of outbreak isolate HG$1 / \mathrm{E} / 15$. We designed RT-PCR primers to amplify segments 2 and 3 from the full-length cDNA on the basis of sequence data of EHDV strains from Japan and Australia available in GenBank. We performed RT-PCR using RNA obtained from an affected cow (no. 9; Table 2) as template; we then purified the RT-PCR products and subjected them to direct sequencing. We used the sequence data to analyze the phylogenetic relationships between EHDV HG-1/E/15 and other EHDV isolates.

We aligned the sequences using ClustalW (11) and constructed phylogenetic trees with MEGA5 using the neighbor-joining method (12); the reliability of the branching orders was evaluated by the bootstrap test (1,000 replicates). Sequence identities between EHDV HG-1/E/15 and the other EHDV isolates were calculated with GENETYX version 10 (GENETYX Corporation, Tokyo, Japan). The results of
Table 2. Neutralizing antibody titers against epizootic hemorrhagic disease virus serotype 6 in paired serum samples collected from affected cattle, Japan, 2015

\begin{tabular}{lcc}
\hline No. & Early onset & After outbreak \\
\hline 1 & $1: 32$ & $1: 64$ \\
2 & $1: 64$ & $1: 32$ \\
3 & $1: 32$ & $1: 32$ \\
4 & $1: 32$ & $1: 64$ \\
5 & $1: 64$ & $1: 32$ \\
6 & $1: 8$ & $1: 64$ \\
7 & $1: 16$ & $1: 64$ \\
8 & $1: 64$ & $1: 64$ \\
9 & $1: 32$ & $1: 64$ \\
10 & $1: 2$ & $1: 64$ \\
11 & $<1: 2$ & $1: 64$ \\
12 & $1: 64$ & $1: 128$ \\
13 & $1: 32$ & $1: 256$ \\
14 & $1: 64$ & $1: 128$ \\
15 & $1: 32$ & $1: 32$ \\
16 & $1: 32$ & $1: 32$ \\
17 & $1: 16$ & $1: 32$ \\
18 & $1: 128$ & $1: 32$ \\
19 & $1: 16$ & $1: 32$ \\
20 & $1: 32$ & $1: 32$ \\
\hline
\end{tabular}

the phylogenetic analysis of segment 2 (DDBJ accession no. LC320035) revealed that HG-1/E/15 clustered with EHDV6 (Figure 2, panel A) and showed highest identity to EHDV6 AUS1981/07 CSIRO 753 (89.68\% nucleotide and 93.51\% amino acid identities). In contrast, the phylogenetic analysis of segment 3 (DDBJ accession no. LC320036) showed that EHDV-6 HG-1/E/15 sorted into the E1 subgroup of the Eastern group (Figure 2, panel B) (8) and had highest identity to the Ibaraki isolate EHDV-2 JPN1959/01 (95.96\% nucleotide and $99.77 \%$ amino acid identities).

\section{Conclusions}

We determined this febrile illness affecting 46 cattle in Japan in 2015 was an epizootic hemorrhagic disease outbreak caused by EHDV-6 infection on the basis of clinical findings, RT-PCR results, neutralization tests, and sequence analyses. Clinical EHDV-6 cases in cattle have been reported in Turkey, Bahrain, Israel, Morocco, Tunisia, Algeria, and Réunion Island $(3,5,13,14)$, but the EHDV-6
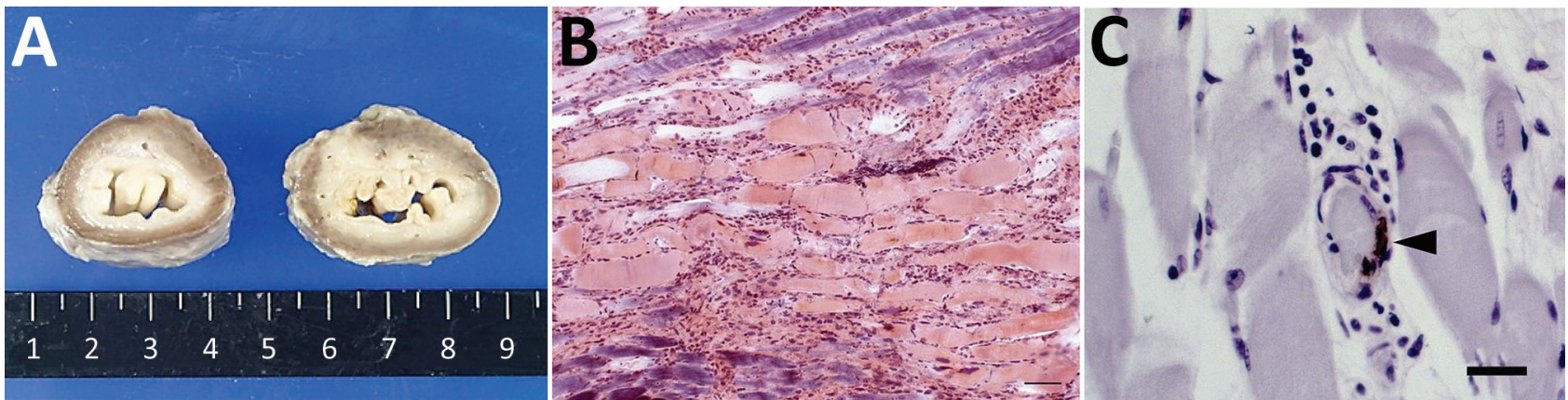

Figure 1. Lesions and epizootic hemorrhagic disease virus serotype 6 (EHDV-6) antigen in esophagus of necropsied cow, Japan, 2015. A) Dilation of lumen. Cross-section of formalin-fixed esophagus of affected cow (right) and control (left). B) Hyaline degeneration of striated muscle accompanied by cell infiltration. Phosphotungstic acid-hematoxylin stain. Scale bar indicates $50 \mu \mathrm{m}$. C) EHDV-6 antigen (arrowhead) in vascular endothelium in esophageal muscularis externa. Immunohistochemical stain. Scale bar indicates $20 \mu m$. 


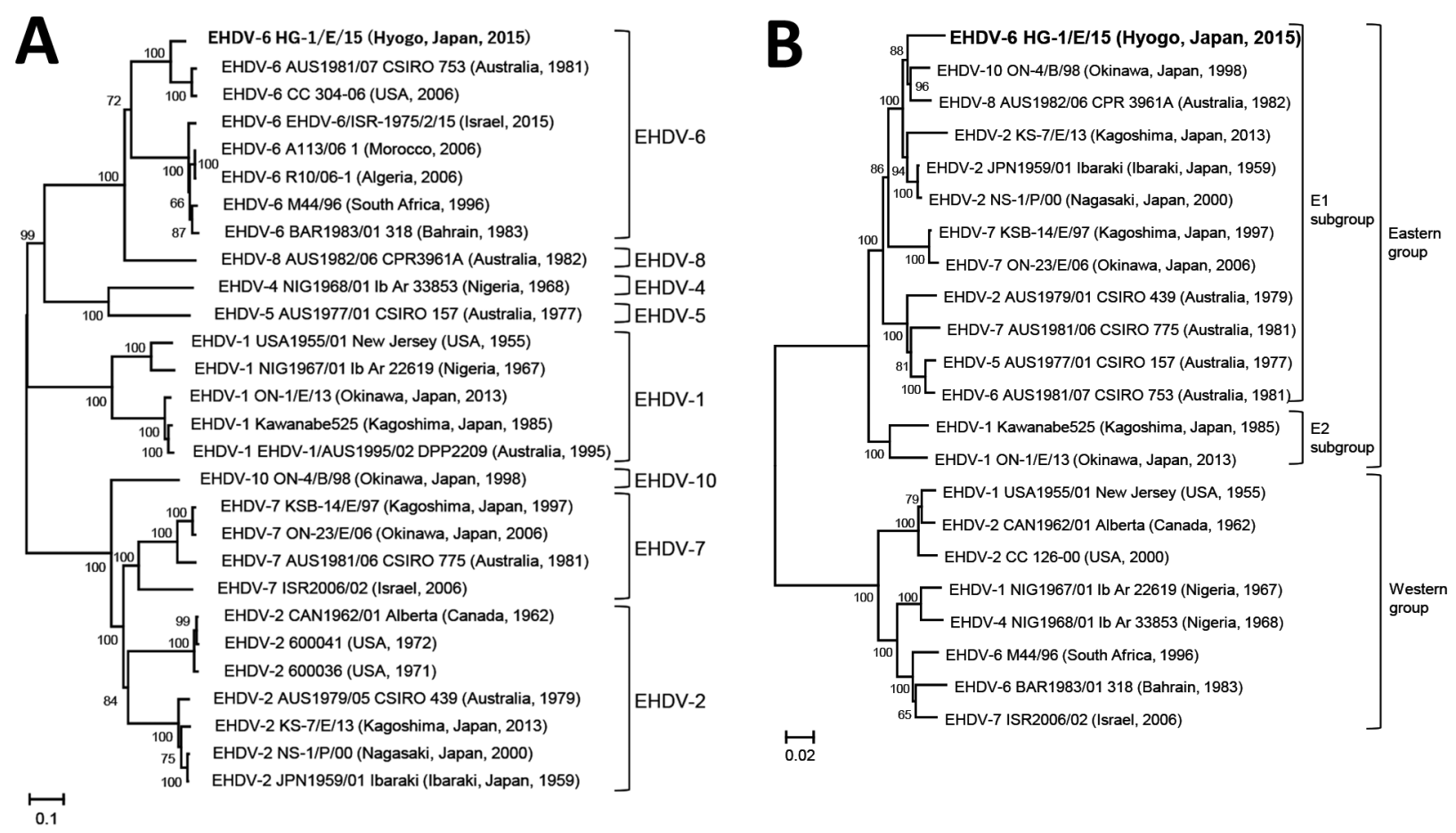

Figure 2. Phylogenetic profile of HG-1/E/15 from EHDV outbreak in cattle, Japan, 2015, compared with reference viruses. A) Phylogenetic profile on the basis of coding region segment 2. EHDV HG-1/E/15 (bold; 2,919 bp) clustered with EHDV-6 strains. B) Phylogenetic profile on the basis of segment 3. EHDV-6 HG-1/E/15 (bold; 2,700 bp) clustered with E1 subgroup of the Eastern group. Virus strain names and location and year of isolation are provided. Scale bars indicate nucleotide substitutions per site. EHDV, epizootic hemorrhagic disease virus.

detected in this outbreak (HG-1/E/15) clustered separately from the EHDV-6 isolates from Africa and the Middle East in the phylogenetic tree analysis of segment 2 (Figure 2, panel A). Because HG-1/E/15 clustered with EHDV isolates from Japan and Australia in the E1 subgroup in the phylogenetic analysis of segment 3 (Figure 2, panel B) (8), HG-1/E/15 appears to be derived from EHDVs circulating in the Asia-Pacific region.

The neutralization tests showed significant increases of antibody titers in 5 cattle, suggesting recent EHDV-6 infection. At the same time, no significant increase of antibody titers was observed with the other 15 cattle. These results suggest that the onset of the epizootic hemorrhagic disease outbreak might have occurred $>3-5$ weeks after the EHDV-6 infection in the 15 seronegative cattle, considering that neutralizing antibody titer increases have been observed to occur in cattle 11-14 to 21-37 days after experimental EHDV-6 infection (15).

The clinical and pathologic findings of this outbreak are similar to those observed for Ibaraki disease in cattle. Thus, EHDV-6 HG-1/E/15 possibly has pathogenic characteristics similar to those of Ibaraki strain EHDV-2 JPN1959/01 in cattle. Further investigations are needed to clarify the genetic characteristics of EHDV-6 HG-1/E/15 to determine why this outbreak occurred.

\section{About the Author}

Dr. Kamomae is a veterinarian at Awaji Livestock Hygiene Service Center in Minamiawaji, Japan. Her research interests are infectious diseases of cattle, pigs, and chickens.

\section{References}

1. Maclachlan NJ, Zientara S, Savini G, Daniels PW. Epizootic haemorrhagic disease. Rev Sci Tech. 2015;34:341-51. http://dx.doi.org/10.20506/rst.34.2.2361

2. World Organisation for Animal Health. Epizootic haemorrhagic disease. In: World Organisation for Animal Health, editor. Manual of diagnostic tests and vaccines for terrestrial animals 2014. Paris: Office International des Epizooties; 2014. p. 1-11.

3. Savini G, Afonso A, Mellor P, Aradaib I, Yadin H, Sanaa M, et al. Epizootic heamorragic disease. Res Vet Sci. 2011;91:1-17. http://dx.doi.org/10.1016/j.rvsc.2011.05.004

4. Omori T, Inaba Y, Morimoto T, Tanaka Y, Ishitani R, Kurogi H, et al. Ibaraki virus, an agent of epizootic disease of cattle resembling bluetongue. I. Epidemiologic, clinical and pathologic observations and experimental transmission to calves. Jpn J Microbiol. 1969;13:139-57. http://dx.doi.org/10.1111/ j.1348-0421.1969.tb00447.x

5. Golender N, Khinich Y, Gorohov A, Abramovitz I, Bumbarov V. Epizootic hemorrhagic disease virus serotype 6 outbreak in Israeli cattle in 2015. J Vet Diagn Invest. 2017;29:885-8. http://dx.doi.org/10.1177/1040638717726826

6. Kitano Y. Ibaraki disease in cattle. In: Coetzer JAW, Tustin RC, editors. Infectious diseases of livestock. 2nd ed. Cape Town (South Africa): Oxford University Press; 2004. p. 1221-5. 
7. Ohashi S, Yoshida K, Watanabe Y, Tsuda T. Identification and PCR-restriction fragment length polymorphism analysis of a variant of the Ibaraki virus from naturally infected cattle and aborted fetuses in Japan. J Clin Microbiol. 1999;37:3800-3.

8. Shirafuji H, Kato T, Yamakawa M, Tanaka T, Minemori Y, Yanase T. Characterization of genome segments 2, 3 and 6 of epizootic hemorrhagic disease virus strains isolated in Japan in 1985-2013: identification of their serotypes and geographical genetic types. Infect Genet Evol. 2017;53:38-46. http://dx.doi.org/ 10.1016/j.meegid.2017.05.010

9. Ohashi S, Yoshida K, Yanase T, Kato T, Tsuda T. Simultaneous detection of bovine arboviruses using single-tube multiplex reverse transcription-polymerase chain reaction. J Virol Methods. 2004;120:79-85. http://dx.doi.org/10.1016/j.jviromet.2004.04.006

10. Maan NS, Maan S, Nomikou K, Johnson DJ, El Harrak M, Madani H, et al. RT-PCR assays for seven serotypes of epizootic haemorrhagic disease virus $\&$ their use to type strains from the Mediterranean region and North America. PLoS One. 2010;5:e12782. http://dx.doi.org/10.1371/journal.pone.0012782

11. Thompson JD, Higgins DG, Gibson TJ. CLUSTAL W: improving the sensitivity of progressive multiple sequence alignment through sequence weighting, position-specific gap penalties and weight matrix choice. Nucleic Acids Res. 1994;22:4673-80. http://dx.doi.org/10.1093/nar/22.22.4673
12. Tamura K, Peterson D, Peterson N, Stecher G, Nei M, Kumar S. MEGA5: molecular evolutionary genetics analysis using maximum likelihood, evolutionary distance, and maximum parsimony methods. Mol Biol Evol. 2011;28:2731-9. http://dx.doi.org/ 10.1093/molbev/msr121

13. Temizel EM, Yesilbag K, Batten C, Senturk S, Maan NS, Mertens PPC, et al. Epizootic hemorrhagic disease in cattle, western Turkey. Emerg Infect Dis. 2009;15:317-9. http://dx.doi.org/ 10.3201/eid1502.080572

14. Sailleau C, Zanella G, Breard E, Viarouge C, Desprat A, Vitour D, et al. Co-circulation of bluetongue and epizootic haemorrhagic disease viruses in cattle in Réunion Island. Vet Microbiol. 2012;155:191-7. http://dx.doi.org/10.1016/ j.vetmic.2011.09.006

15. Batten CA, Edwards L, Bin-Tarif A, Henstock MR, Oura CAL. Infection kinetics of epizootic haemorrhagic disease virus serotype 6 in Holstein-Friesian cattle. Vet Microbiol. 2011;154:23-8. http://dx.doi.org/10.1016/j.vetmic.2011.06.018

Address for correspondence: Hiroaki Shirafuji, Kyushu Research Station, National Institute of Animal Health, National Agriculture and Food Research Organization, 2702 Chuzan, Kagoshima 891-0105, Japan; email:shirah@affrc.go.jp

\section{July 2013: Vectorborne Infections}

- Transmission of Streptococcus equi Subspecies zooepidemicus Infection from Horses to Humans

- Travel-associated Illness Trends and Clusters, 2000-2010

- Quantifying Effect of Geographic Location on Epidemiology of Plasmodium vivax Malaria
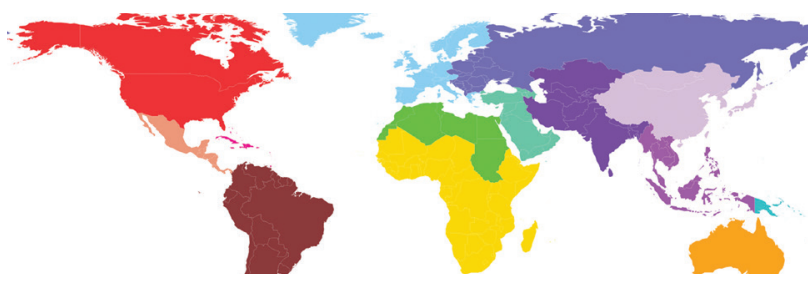

- Mutation in Spike Protein Cleavage Site and Pathogenesis of Feline Coronavirus

- Pneumococcal Serotypes before and after Introduction of Conjugate Vaccines, United States, 1999-2011

- Influence of Pneumococcal Vaccines and Respiratory Syncytial Virus on Alveolar Pneumonia, Israel

- Avian Metapneumovirus Subgroup C Infection in Chickens, China

- Human Alveolar Echinococcosis in Kyrgyzstan

- Molecular Epidemiologic Source Tracking of Orally Transmitted Chagas Disease, Venezuela

- Unique Clone of Coxiella burnetii Causing Severe Q Fever, French Guiana
- Babesia microti Infection, Eastern Pennsylvania, USA

- Reemergence of Chikungunya Virus in Bo, Sierra Leone

- Novel Bartonella Agent as Cause of Verruga Peruana

- Schmallenberg Virus among Female Lambs, Belgium, 2012

- Psychrobacter arenosus Bacteremia after Blood Transfusion, France

- Ciprofloxacin-Resistant Campylobacter spp. in Retail Chicken, Western Canada

- Asynchronous Onset of Clinical Disease in BSE-Infected Macaques

- Prevalence of Nontuberculous Mycobacteria in Cystic Fibrosis Clinics, United Kingdom, 2009

- Reducing Visceral Leishmaniasis by Insecticide Impregnation of Bed-Nets, Bangladesh

- Genetic Variants of Orientia tsutsugamushi in Domestic Rodents, Northern China

- MDR TB Transmission, Singapore

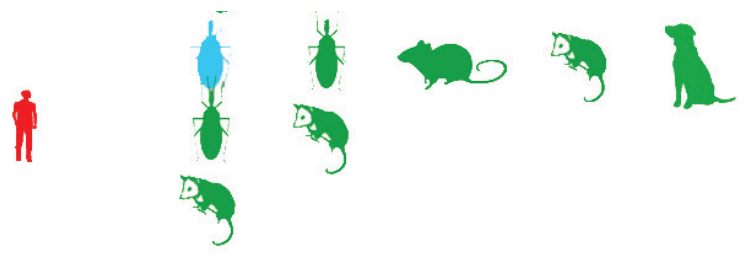

